\title{
Tectonics and climate for the last ca. 35,000 years in the Kumaun Himalaya, India
}

\author{
BS Kotlia \\ Department of Geology, Kumaun University, Nainital, 263 002, INDIA
}

For correspondence,E-mail: bskotlia@yahoo.com

The Kumaun Lesser Himalayan terrain is defined by very active intracrustal thrusts where the strain progressively builds up due to horizontal compression. A number of thrusts/faults parallel or oblique to the intracrustal boundary thrusts were reactivated in the Late Pleistocene. The neotectonic movements along the main and associated faults are manifest in the pronounced geomorphic rejuvenation of the landscape such as off-setting of the country rocks, formation and dislocation of terraces and colluvial cones, deposition of unsorted huge gravels and debris flows, structurally-controlled meandering, triangular fault facets, fault scarps and steel waterfalls. The resultant stream ponding culminated in the formation of lakes behind recently uplifted blocks upstream of the active faults. Very recently, our group has discovered a number of such tectonic lakes in the Kumaun Himalaya, represented by 10-13 m thick succession of clays and carbonaceous muds.

We suggest that the Kumaun Himalaya experienced four major tectonic events at ca. $35 \mathrm{ka}, 22-21 \mathrm{ka}, 10 \mathrm{ka}$ and 1.5-1.3 ka $\mathrm{BP}$. These events were responsible either for formation of lakes or closure of some of the existing ones. Four minor magnetic reversals are detected in the palaeolake profiles at ca. $35 \mathrm{ka}$, $28-25 \mathrm{ka} .22-21 \mathrm{ka}$ and $8 \mathrm{ka} \mathrm{BP}$. This is the first report of the minor reversals in the lacustrine systems of the Indian subcontinent.

Using a variety of multidisciplinary techniques, e.g., chronological, isotopes, clay mineralogy, elemental analysis and pollen spectra, following climatic events are obtained for the Kumaun Himalaya. Climatic amelioration (ca. 34.3-32.2 ka BP), short spell of aridity (32.2-31.3 ka BP), warm and moist conditions (31.3-30.0 ka BP), cool/arid climate (30.0-28.9 ka BP), warm/humid conditions (28.9-27.4 ka BP), aridity (27.4-26.8 ka $\mathrm{BP})$, humid/moist conditions (26.8-25.3 ka BP), semi-arid conditions (25.3-24.5 ka BP), humid conditions (24.5-22.4 ka BP), aridity (22.4-21.7 ka BP), humid conditions (21.7-20.0 ka BP), arid conditions (20.0-18.0 ka BP), semi-arid conditions (18.0$17.0 \mathrm{ka} \mathrm{BP})$, arid climate (17.0-15.2 ka BP), humid phase (7.3-4.2 ka BP) and aridity from ca. 4 ka BP onwards. Figure 1 shows high resolution climatic changes between ca. 31 and $22 \mathrm{ka} \mathrm{BP}$.

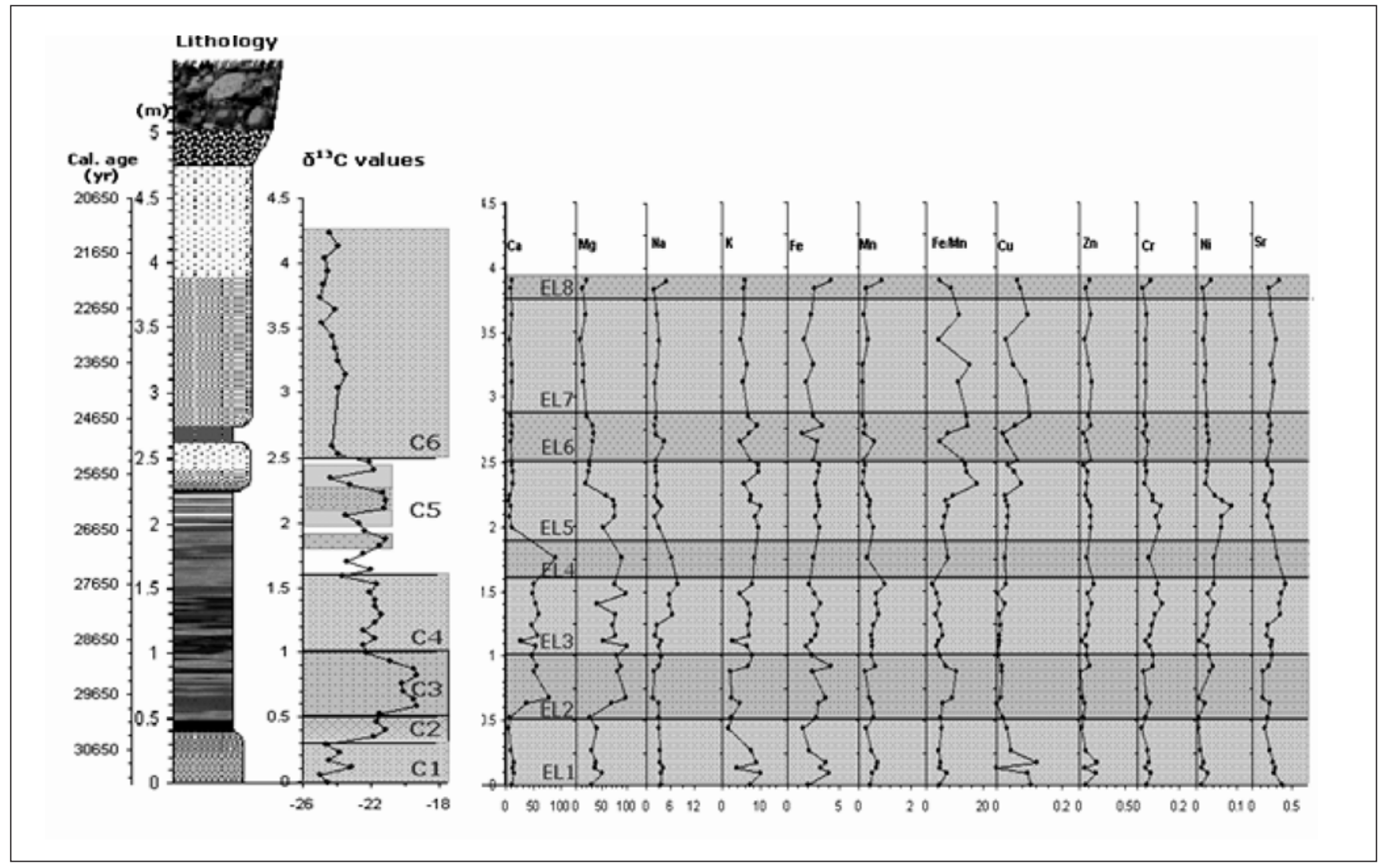

FIGURE 1. Climatic changes between ca. 31 and 22 ka BP in the Dulam area, Kumaun Lesser Himalaya, India 